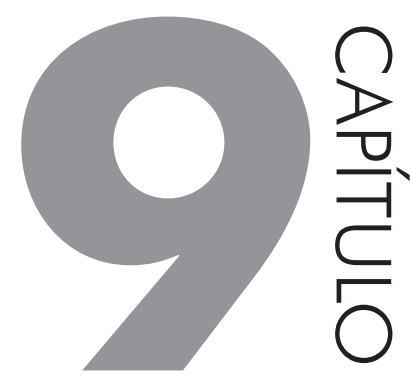

\title{
O ATLAS LINGUÍSTICO DO AMAZONAS - ALAM
}

MARIA LUIZA DE CARVALHO CRUZ-CARDOSOำ

\section{INTRODUÇÃO}

Este trabalho apresenta, em linhas gerais, o desenvolvimento do Atlas Linguístico do Amazonas (ALAM), desenvolvido como tese de Doutorado na UFRJ e apresentado no ano de 2004. O ALAM ainda se encontra em fase de publicação e tem uma grande importância para a região, por ser o primeiro trabalho a ser desenvolvido no âmbito da Geolinguística Pluridimensional no Amazonas, considerando a ausência de pesquisas dialectológicas nessa área. $\mathrm{O}$ atlas foi desenvolvido na perspectiva da Geografia Linguística e da Sociolinguística Va-

1 O ALAM era um sonho meu, de caráter acadêmico, quase impossível de ser realizado, devido à grande extensão territorial do Amazonas. Ao desembarcar no RJ, proveniente de Manaus, procurei, meio sem esperança, a Professora Silvia Brandão, para me orientar na elaboração do Atlas. Para minha surpresa, a Professora me recebeu com imensa disponibilidade e, sem me conhecer, acreditou que eu poderia realizar esse Projeto, sozinha, no Curso de Doutorado. A ela, minha imensa gratidão, pela brilhante orientação que recebi, pela credibilidade que em mim depositou para a execução deste Projeto e por ter sido minha grande companheira nesta viagem dialetal pelo Amazonas. 
riacionista, preocupando-se em controlar, de forma sistemática, as variáveis gênero e faixa etária.

Para tanto, foram selecionados nove municípios de maior representatividade para o Amazonas, segundo critérios de natureza histórica, geográfica, demográfica e socioeconômica. Foram também considerados 06 pontos de inquérito, dos 16 sugeridos por Nascentes (1958) para o Amazonas; 02 pontos de inquérito sugeridos pelo Projeto do Atlas Linguístico do Brasil - ALiB e a divisão político-administrativa do Estado, de 05/10/1989, que o segmentou em 9 microrregiões homogêneas, com base nas bacias hidrográficas dos principais afluentes do Rio Amazonas. Manaus não foi selecionada, por ser a capital do Amazonas e nela se concentrar a grande maioria do contingente populacional do Estado, o que demandaria uma pesquisa mais ampla de cunho sociolinguístico. Foram, então, selecionados os seguintes municípios: Barcelos (Microrregião do Alto Rio Negro), Tefé (Microrregião do Jutaí-Solimões-Juruá), Benjamin Constant (Microrregião do Alto Solimões), Eirunepé (Microrregião do Juruá), Lábrea (Microrregião do Purus), Humaitá (Microrregião do Madeira), Manacapuru (Microrregião do Rio Negro - Solimões), Itacoatiara (Microrregião do Médio Amazonas) e Parintins (Microrregião do Baixo Amazonas), conforme figura a seguir:

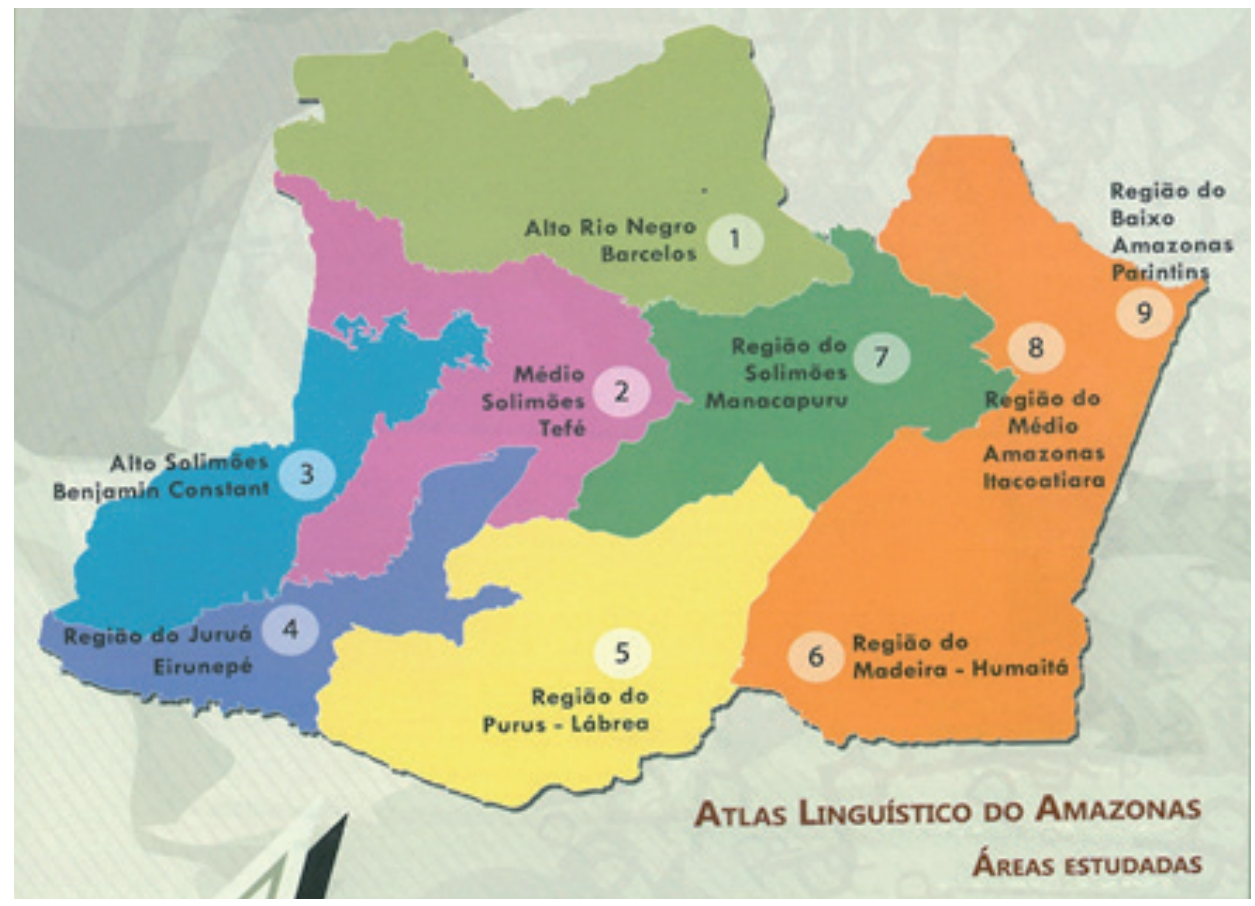

Figura 1 Mapa dos Pontos de Inquérito do ALAM. 


\section{METODOLOGIA}

Foram entrevistados 06 informantes por ponto de inquérito, totalizando 54, sendo um homem e uma mulher, em cada uma das seguintes faixas etárias: 18-35 anos, de 36-55 anos e 56 em diante. Os informantes tinham, no máximo, até a $4^{a}$ série do Ensino Fundamental; eram naturais das localidades selecionadas e tinham pais e cônjuges da região em estudo. Observou-se, também, o fato de não terem se afastado da localidade por mais de um terço de suas vidas.

Foi elaborado um questionário com 483 questões, divididas em duas seções: questionário fonético-fonológico (QFF), com 156 questões, e questionário semântico-lexical (QSL), com 327 perguntas. As questões foram elaboradas com base em trabalhos que versavam sobre agricultura e pesca, nos questionários dos atlas já publicados e em algumas questões do Projeto ALiB.

O ALAM dispõe de um programa computacional específico, denominado ALAM/ MVL (Mapeamento de Variação Linguística), com um banco de dados que permite inserir todos os conceitos, dados dos informantes, das localidades e todas as respostas obtidas, tanto fonéticas quanto lexicais. Para o QFF, o programa oferece um conjunto de símbolos do IPA, e, para o QSL, uma simbologia de caracteres, selecionados da fonte wingdings 2 . Todos os dados foram inseridos no programa computacional, obtendo-se um total de 18.324 registros.

No QFF, procurou-se observar todos os fenômenos que dizem respeito às realizações dos fonemas vocálicos em todas as posições do vocábulo e foram também elaboradas questões privilegiando a redução dos ditongos /ey/ a [e] e /ow/ a [u]. Observou-se, ainda, outro importante fenômeno que existe na fala da Amazônia, que é o alteamento da vogal tônica /o/ para [u], em qualquer posição no vocábulo, como em "tudo" ['todo]. Quanto aos fonemas consonantais, entre outros aspectos, procurou-se registrar a realização das vibrantes, das laterais e do /S/, em todos os contextos. A seguir, apresenta-se um exemplo de Carta Fonética: 


\section{MAPA 02}

Atlas Lingüistico do Amazonas - ALAM

Carta Fonética

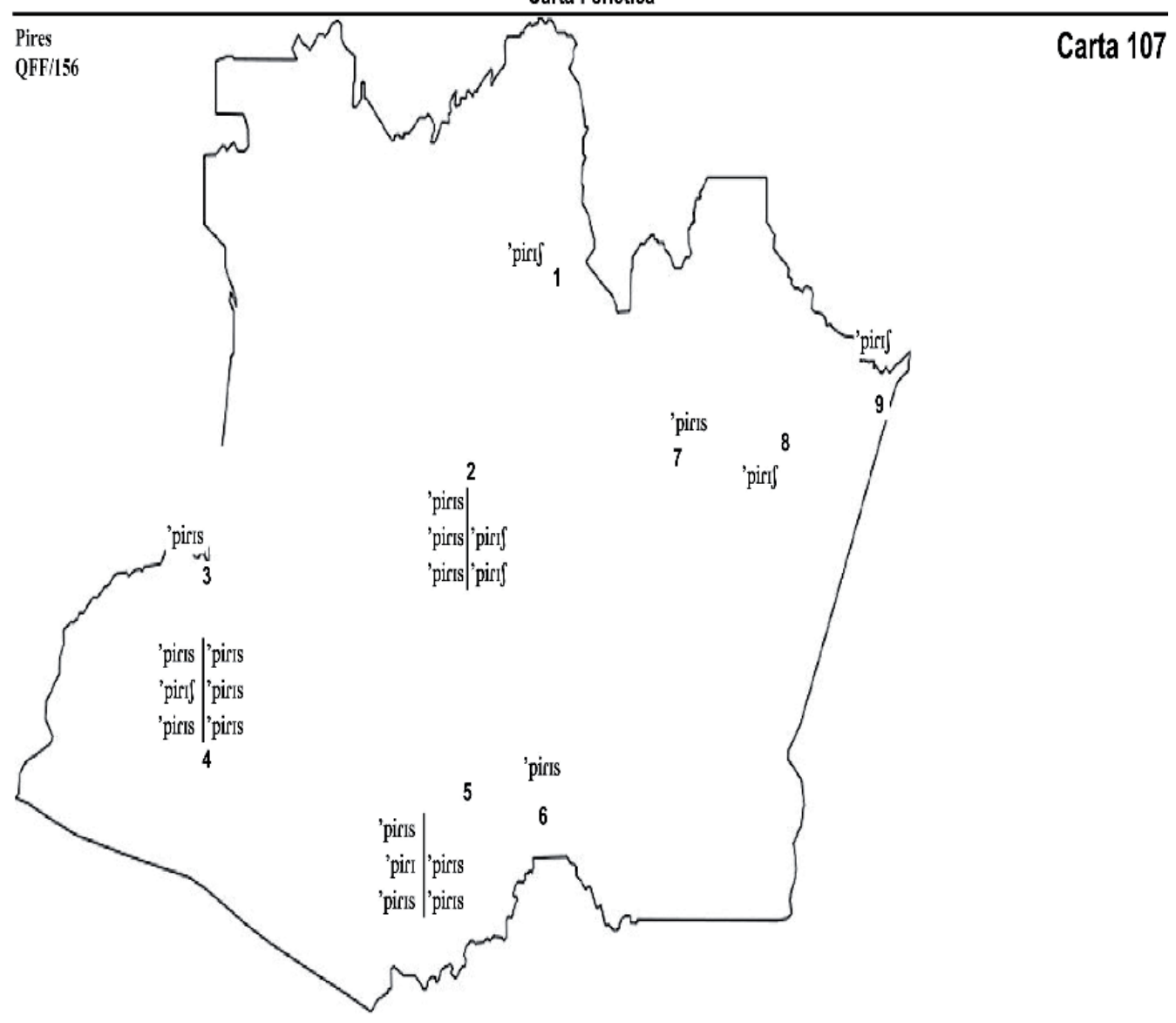

Figura 2 Exemplo de Carta Fonética da realização do /S/.

O QSL foi dividido em três campos semânticos: Meio Físico, Meio Biótico e Meio Antrópico. O Meio Físico abrangeu questões sobre a terra e os rios, e fenômenos atmosféricos; no Meio Biótico, contemplaram-se questões sobre a fauna e a flora; e no Meio Antrópico, questões relativas ao homem, atividades de produção (agricultura, caça e pesca, meios de transporte fluvial). A seguir, segue um exemplo de Carta Semântico-Lexical: 


\section{MAPA 03}

Atlas Lingüistico do Amazonas - ALAM

Carta Semântico-Lexical

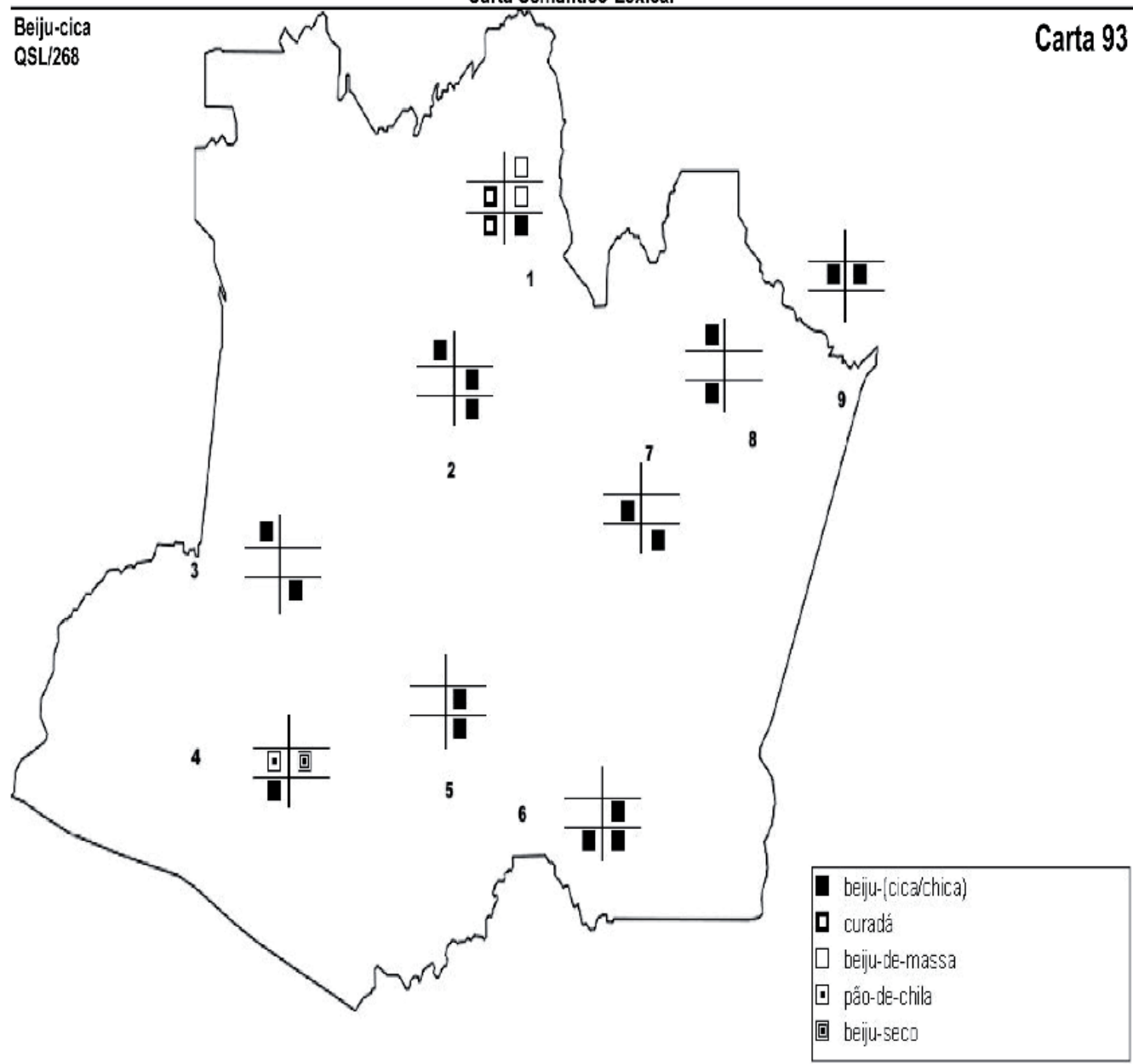

Alimento feito de massa de mandioca ralada sem a casca e sem a pele.

Figura 3 Exemplo da Carta Semântico-Lexical.

Essa carta faz parte das questões relativas ao Meio Antrópico, na parte que se refere à agricultura. Foram investigados os itens lexicais utilizados na roça, quanto ao cultivo da juta e da mandioca, tendo em vista que esse tipo de agricultura é característico da região em foco. 
Além dos questionários, foram realizadas elocuções livres, semidirigidas, que foram transcritas posteriormente por alunos bolsistas PIBIC/UFAM e constituem, hoje, um banco de dados disponível para a consulta e a realização de diversos estudos, não só fonéticos ou lexicais, mas também morfossintáticos, prosódicos etc.

As questões do ALAM culminaram na elaboração de 257 cartas linguísticas, sendo 107 cartas fonéticas e 150 cartas semântico-lexicais. O Atlas é apresentado em dois volumes: o primeiro contendo uma introdução de caráter metodológico e o segundo, as cartas².

Foram, ainda, elaboradas 41 cartas especiais, denominadas de Derivadas (DER), resultantes da reunião de respostas:
a) Oriundas de questões do QFF.
b) Oriundas de questões do QFF e do QSL.
c) Oriundas de questões do QSL.
d) Oriundas de questões do QSL - Meio Biótico.

Algumas delas registram diferentes itens lexicais para um mesmo conceito; outras retratam diversidade biótica ou etnográfica regional. Essas cartas devem ser lidas da seguinte forma:

a) Indica-se à esquerda, a seguir do conceito, e após a sigla DER, já referida, o tipo de questionário e número das perguntas que lhes deram origem.

b) Nas legendas das cartas derivadas (DER) que retratam a diversidade biótica regional, itens lexicais que constituem variantes de um mesmo elemento são seguidas de um número entre parênteses, que não só os identifica como variantes, mas também remete à sua caracterização científica.

c) Nas cartas derivadas (DER), as respostas foram reunidas para serem apresentadas de acordo com a mesma característica científica a que pertencem.

A seguir, um exemplo de Carta Derivada (DER):

2 Como se pode observar no Mapa 2, os dados fonéticos foram transcritos, utilizando-se o Alfabeto Fonético Internacional (IPA). Todas as transcrições foram realizadas pela própria pesquisadora. As entrevistas foram realizadas in loco, sendo gravadas em 84 minidiscos. 


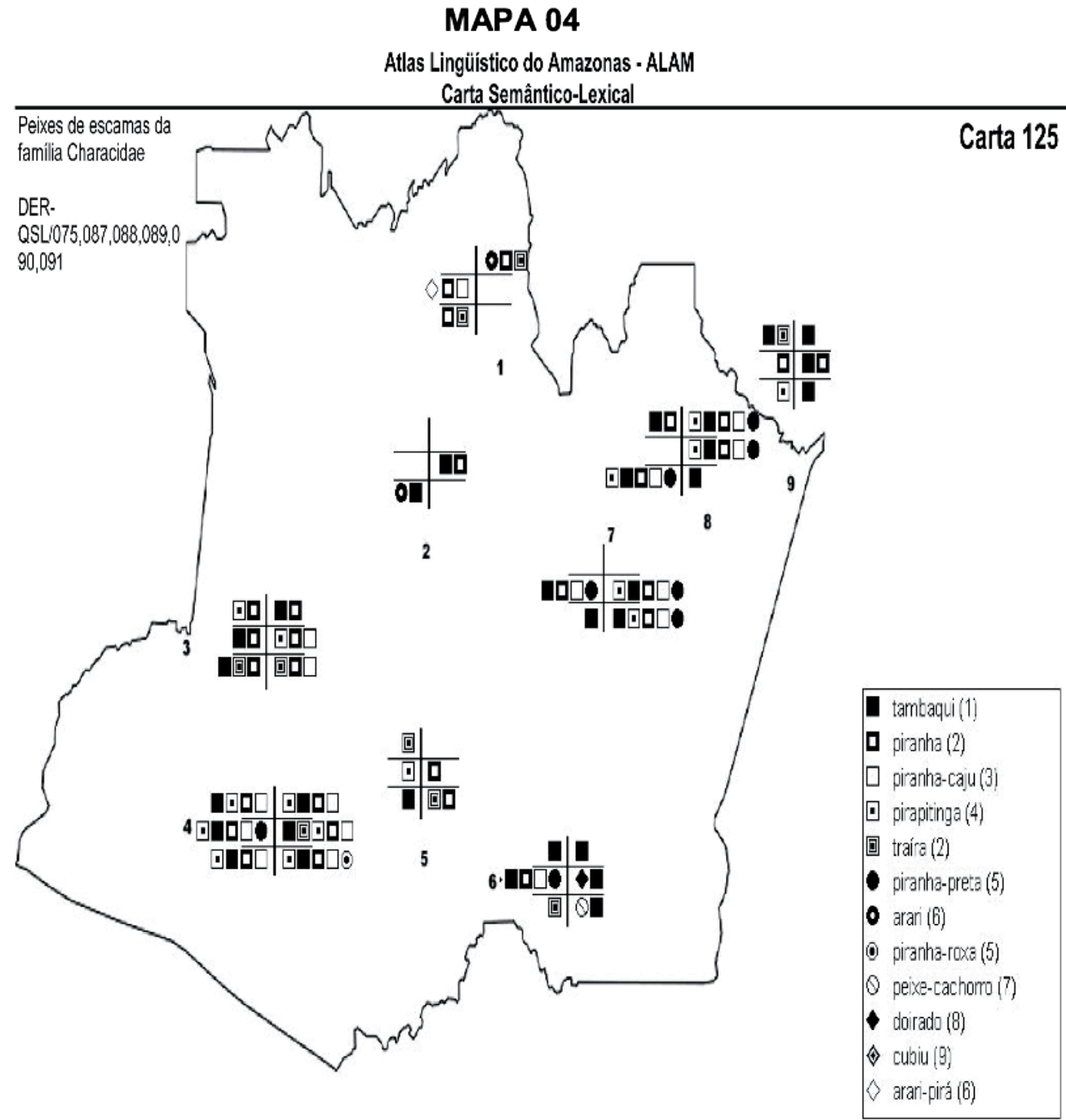

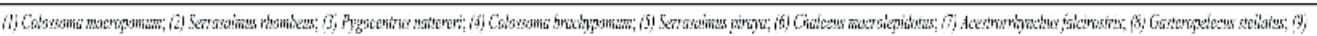

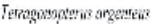

Figura 4 Exemplo de Carta Semântico-Lexical (DER).

\section{RESULTADOS OBTIDOS}

O Atlas Linguístico do Amazonas - ALAM não teve por objetivo interpretar os resultados obtidos por meio das cartas fonéticas e das cartas semântico-lexicais, mas pôde apresentar um panorama de alguns traços que tipificam o conjunto dos falares amazonenses, segundo os dados observados na elaboração do ALAM. Traços esses que têm servido de parâmetro para o prosseguimento de 
novas pesquisas na região. Dessa forma, foram observados os seguintes resultados em termos fonéticos:

a) Há significativa ocorrência de abaixamento das vogais mediais pretônicas $[\varepsilon, \supset]$, embora se tenham encontrado também significativos índices de frequência de $[e, o]$, bem como de alteamento [i, u], em alguns vocábulos.

b) O alteamento, em contexto tônico, da vogal posterior média fechada, que, há muitos anos, é considerada como típico dos falares do Amazonas e do Pará, teve baixíssima representatividade na região.

c) Os ditongos /ei/ e /ou/, nos contextos considerados condicionadores de monotongação, apresentam significativos índices de produtividade.

d) Predominam as variantes alveolares de $-S$ pós-vocálico nos contextos medial e final de vocábulo, tendo-se, no entanto, observado que as variantes pós-alveolares apresentam grande produtividade basicamente em três localidades: (1) Barcelos, (8) Itacoatiara e (9) Parintins.

e) O R- forte pré-vocálico inicial de vocábulo ou intervocálico é produzido, quase de forma categórica, como fricativa glotal surda.

f) $\mathrm{O} / \mathrm{t} / \mathrm{e}$ o /d/ realizam-se, categoricamente, como africadas pós-alveolares diante de /i/ e como oclusivas alveolares, nos demais contextos. O /l/, em contexto pós-vocálico, concretiza-se como semivogal posterior.

Em relação aos dados provenientes do QSL, foram observados os seguintes resultados:

a) Não foram encontradas variantes para arco-íris (Carta 11), considerando a diversidade observada em atlas brasileiros e europeus.

b) Os itens lexicais cunhantã (Carta 40) e curumim (Carta 41), de origem tupi, respectivamente, moço e moça pequena de até 10 anos de idade, parecem estar em desuso, apresentando ocorrência apenas em Barcelos (Ponto 1), Manacapuru (Ponto 7), Itacoatiara (Ponto 8) e Parintins (Ponto 9). O mesmo ocorre com a forma púcaro (Carta 63), presente na fala dessas três últimas localidades, sendo mais difundida a variante caneco.

c) Em relação ao item lexical cambalhota (Carta 76), comum a cinco dos atlas publicados, verifica-se o predomínio da variante carambola, sendo que, nas localidades de Eirunepé (Ponto 4) e Lábrea (Ponto 5), ocorreu na fala de mulheres da segunda faixa etária a forma cangapé, presente no Atlas Linguístico da Paraíba.

d) O item lexical macaca (Carta 82), registrado no Atlas Linguístico do Paraná, é empregado em todas as localidades observadas para designar a brincadeira infantil conhecida como amarelinha. 
e) O item lexical peteca (Carta 77) é registrado como bolinha de gude, o que difere no registro de outros atlas.

\section{CONSIDERAÇÕES FINAIS}

O Atlas Linguístico do Amazonas - ALAM encontra-se à disposição dos professores e alunos, na Biblioteca Central da Universidade Federal do Amazonas (UFAM), e oferece um leque de perspectivas para outras pesquisas, tendo em vista o corpus coletado e o questionamento linguístico que os dados das cartas fonéticas e semântico-lexicais propiciam. Em breve, pretende-se publicar o ALAM e disponibilizar, em CD, o programa computacional que contém seus dados.

Vale ressaltar que, a partir deste trabalho, muitas outras pesquisas têm sido realizadas no Amazonas, particularmente, na UFAM, considerando os dados do ALAM e dentro da mesma perspectiva de investigação. As pesquisas acontecem no âmbito da Iniciação Científica (PIBIC) e dos Cursos de Especialização, de Mestrado e de Doutorado. Ressalte-se, ainda, que dois outros atlas já foram realizados, na UFAM, como Dissertação de Mestrado, no âmbito da Dialetologia Pluridimensional: o Atlas dos Falares do Baixo Amazonas - AFBAM, por Roseanny Brito, em 2011, e o Atlas Linguístico dos Falares do Alto Rio Negro - ALFARiN, por Jeiviane Justiniano, em 2012. Ambos ainda não publicados. Dessa forma, pretende-se, dentro dos próximos anos, ter um registro mais específico do modo de falar do amazonense, o que, sem dúvida, contribuirá para o conhecimento das diversas variedades brasileiras do Português.

\section{REFERÊNCIAS BIBLIOGRÁFICAS}

AGUILERA, Vanderci de Andrade. Atlas Linguístico do Paraná. 1 v. Curitiba: Imprensa Oficial do Estado do Paraná, 1994.

ARAGÃO, Maria do Socorro; MENEZES, Cleuza de. Atlas Linguístico da Paraíba. 2 v. Brasília: UFPB/CNPq, 1984.

BENCHIMOL, Samuel. Amazônia - Formação social e cultural. Manaus: Valer, Editora Universidade do Amazonas, 1999.

BRANDÃO, Silvia Figueiredo. A geografia linguística do Brasil. São Paulo: Ática, 1991.

BRITO, Roseanny de Melo. Atlas dos Falares do Baixo Amazonas - AFBAM. 2011. Dissertação (Mestrado em Sociedade e Cultura na Amazônia) - Instituto de Ciências Humanas e Letras, Universidade Federal do Amazonas, Manaus, 2011.

CARDOSO, Suzana Alice Marcelino. Atlas Linguístico de Sergipe - II . Vol. 1, ALS - II, Vol. 2, Introdução às cartas; acompanhado por um conjunto de mapas. 2002. Tese (Doutorado em Letras Vernáculas) - Faculdade de Letras, Universidade Federal do Rio de Janeiro, Rio de Janeiro, 2002. 
; FERREIRA, Carlota. A Dialectologia no Brasil. São Paulo: Contexto, 1994.

JUSTINIANO, Jeiviane dos Santos. Atlas dos Falares do Alto Rio Negro - ALFARiN. 2012. Dissertação (Mestrado em Letras) - Instituto de Ciências Humanas e Letras, Universidade Federal do Amazonas, Manaus, 2012.

SILVA NETO, Serafim da. Guia para estudos dialectológicos. 2. ed. melh. e ampl. Belém: Conselho Nacional de Pesquisas, Instituto Nacional de Pesquisas da Amazônia, 1957. 